\title{
Left ventricular outflow tract obstruction in complete transposition of the great arteries with intact ventricular
} septum

A cross sectional echocardiography study

\author{
PETER J ROBINSON, RICHARD K H WYSE, FERGUS J MACARTNEY \\ From the Department of Paediatric Cardiology, The Hospital for Sick Children, Great Ormond Street, London
}

SUMMARY The roles of posterior bulging of the interventricular septum (septal bulge) and of systolic septal mitral apposition in patients with simple transposition of the great arteries are not known. Cross sectional echocardiograms of $\mathbf{4 0}$ such patients were reviewed (after exclusion of those with fixed left ventricular outflow tract obstruction) and haemodynamic findings were compared with long and short axis measurements within the left ventricle. There was no significant correlation between the degree of septal bulge and systolic gradient across the left ventricular outflow tract, but septal bulge correlated weakly with systolic right ventricular pressure and inversely with pulmonary arteriolar resistance index. Systolic left ventricular outflow gradient was inversely related to the minimum systolic distance between the anterior mitral leaflet and interventricular septum. No patients without complete systolic apposition of the anterior mitral leaflet and interventricular septum had a left ventricular outflow gradient $>20 \mathrm{~mm} \mathrm{Hg}$. Conversely, even when cross sectional echocardiography showed apparently total obstruction of the left ventricular outflow tract at some time in systole there was often no significant gradient detected during haemodynamic study. In the short axis cuts closeness of the papillary muscles to the interventricular septum or to each other was unrelated to systolic gradient. This study shows that (a) cross sectional echocardiography can identify fixed obstruction of the left ventricular outflow tract in simple transposition of the great arteries; (b) the degree of septal bulge, unless complicated by fibrous thickening of the anterior mitral leaflet and interventricular septum, is unrelated to the gradient across the left ventricular outflow tract; (c) the absence of systolic septal/mitral apposition excludes a significant gradient at that site across the left ventricular outflow tract; and (d) papillary muscle geometry is unrelated to dynamic gradients across the left ventricular outflow tract in this condition.

Left ventricular outflow tract obstruction is a common accompaniment of complete transposition of the great vessels. Whereas this additional defect is beneficial in the untreated condition, ${ }^{1}$ it complicates repair of the transposition, whether this is by transposition of venous inflow or switching of the great arteries.

It has long been recognised that the anatomical bases for left ventricular outflow tract obstruction differ greatly in patients with and without an associated

Requests for reprints to Professor F J Macartney, The Hospital for Sick Children, Great Ormond Street, London WCIN 3JH.

Accepted for publication 7 May 1985 ventricular septal defect. ${ }^{2}$ When a ventricular septal defect is present the varieties of left ventricular outflow tract obstruction are diverse but well understood and easily recognised by angiocardiography. By contrast the genesis of left ventricular outflow tract obstruction when the ventricular septum is intact remains undetermined.

Certain forms of left ventricular outflow tract obstruction with intact ventricular septum are anatomically easily recognisable. These include pulmonary valve stenosis, which is rare, membranous subpulmonary stenosis (analogous to discrete membranous subaortic stenosis), which is located within a few millimetres of the pulmonary valve, and anomalous 
attachment of the mitral valve to the ventricular septum (clockwise rotation of the mitral valve) ${ }^{34}$ All of these are much less common than posterior septal bulge. Shaher and colleagues recognised that in transposition of the great vessels with intact ventricular septum there was a tendency for the ventricular septum to bulge into the left ventricle (septal bulge) ${ }^{2}$; this was originally attributed to septal hypertrophy. Yacoub and colleagues showed that when left ventricular pressure rose after the pulmonary trunk had been banded in preparation for an arterial switch operation, the septal bulge became much less prominent. ${ }^{5}$

It has been suggested, however, that septal bulge itself causes left ventricular outflow tract obstruction in some patients. ${ }^{6}$ In certain cases there is also a discrete line of endocardial thickening on the crest of the bulge, corresponding to the point at which the free edge of the anterior mitral leaflet would be expected to come into contact with the ventricular septum at some stage in the cardiac cycle. ${ }^{6-8}$ The precise relation between septal bulge and left ventricular outflow tract obstruction in simple complete transposition remains unknown.

Cross sectional echocardiography seems to be an ideal method of investigating this situation, especially since it not only yields haemodynamic information about septal bulge and motion of the anterior leaflet of the mitral valve (particularly in parasternal and apical long axis views of the left ventricle) but also demonstrates the mitral papillary muscles and chordae tendinae. ${ }^{9}$ The technique should be able to display subpulmonary diaphragmatic obstruction with the same accuracy as it does subaortic obstruction, ${ }^{10}$ although Daskalopoulos and colleagues were unable consistently to identify the exact site of subpulmonary obstruction in a mixed group of patients who had transposition with and without ventricular septal defects. ${ }^{11}$

Since left ventricular outflow tract obstruction can result from insertion of the mitral valve into the ventricular septum itself, ${ }^{12}$ it is also possible that obstruction may result when the papillary muscles are inserted into the free wall of the left ventricle but unusually close to the interventricular septum. Furthermore, a recent postmortem study suggested that the angle between the great vessels may be related to the systolic gradient between the left ventricle and pulmonary trunk by virtue of the degree of wedging of the posterior great vessel in the left ventricular outflow tract. ${ }^{13}$ Cross sectional echocardiography was proposed as an ideal way of further testing this hypothesis.

We therefore undertook this study to attempt to answer the following questions. Firstly, could cross sectional echocardiography be used to identify fixed abnormalities in the mitral valve or its tension apparatus, in the left ventricular outflow tract, or in the pulmonary valve which cause an important systolic gradient between left ventricle and pulmonary trunk? Secondly, we wanted to determine whether there was a relation between the degree of septal bulge or the minimum systolic distance between the anterior mitral leaflet and the ventricular septum and peak gradient from left ventricle to pulmonary trunk that might be useful clinically. Thirdly, we wanted to ascertain whether there was a correlation between the relation of the papillary muscles to each other or to the ventricular septum and the peak systolic gradient from left ventricle to pulmonary trunk. Finally, was great vessel angle related to systolic gradient from left ventricle to pulmonary trunk?

\section{Patients and methods}

From March 1980 to June 1984, 79 patients at this hospital underwent cross sectional echocardiography and cardiac catheterisation for investigation of simple transposition of the great vessels. Cross sectional echocardiograms were performed by means of an Advanced Technology Laboratory mark V mechanical sector scanner with a 3.5 or $5.0 \mathrm{MHz}$ transducer. Studies were stored on three quarter inch Sony tape and reviewed on a Sony PS5300 playback system. Cardiac catheterisation was performed by standard techniques, but oxygen uptake was not routinely measured. Oxygen consumption was, however, estimated ${ }^{14}$ and incorporated into the Fick equation for flow and subsequent resistance calculations.

All the echocardiograms were retrospectively reviewed in ignorance of the haemodynamic results, and still frame Polaroid photographs were taken of the left ventricle at end systole in the parasternal long axis cut (Fig. 1) and in the parasternal short axis cut (Fig. 2). The short axis pictures were taken at any stage in the cardiac cycle at which the mitral papillary muscles were clearly visible (at end diastole where possible).

The relation of the great vessels to each other was expressed as an angle (Fig. 3) measured from still frame Polaroid photographs in the parasternal short axis cut. Ratios derived from the measurements of the left ventricle were compared with haemodynamic measurements. Those patients regarded by two observers to have a fixed (see Results) abnormality of the left ventricular outflow tract or pulmonary valve on cross sectional echocardiography were excluded from further analysis.

The ratios $c:(a+b)$ and $c: g$ were taken as measures of the degree of septal bulge and $a:(a+b)$ as a measure of the eccentricity of septal bulge in the long axis cuts (Fig. 1). The ratio d:g was taken as a measure of the closeness of the anterior mitral leaflet to the interventricular septum at end systole (d) compared with the 


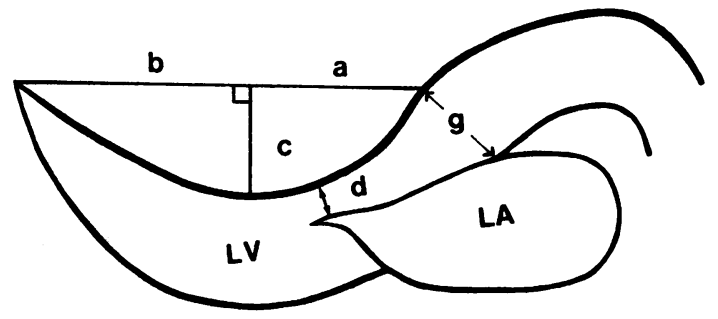

Fig. 1 Diagrammatic representation of parasternal long axis cut showing the left ventricle ( $L V)$, left atrivon (LA), and where the measurements $a, b, c, d$, and $g$ were made on the still frame photographs. $g$ is the diameter of the pulmonary trunk at the level of the pulmonary value; $d$ is the smallest distance in systole between the anterior mitral leaflet and the interventricular septum; the line $a+b$ joins the anterior point of insertion of the pubmonary valve and the most apical point of the endocardial surface of the left ventricular cavity; $c$ is a perpendicular line from the point of maximum septal bulge back to the line $a+b$ that determines the distances $a$ and $b$.

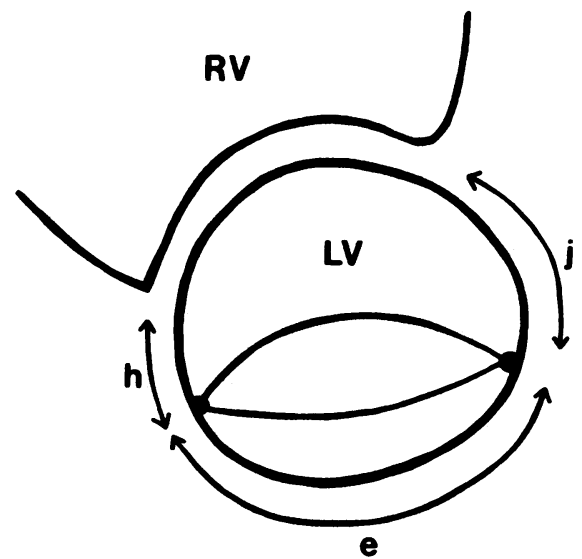

Fig. 2 Diagrammatic representation of parasternal short axis at the level of the tips of the mitral valve cut showing the left ventricle $(L V)$, right ventricle $(R V)$ and where the measurements $e, j$, and $h$ were made from the still frame photographs. $e$ is the distance between the endocardial attachments of the anterolateral and posteramedial papillary muscles. $h$ and $j$ are the distances of the papillary muscles from the interventricular septum and $f$ (see text) is the endocardial LV circumference.

diameter of the pulmonary valve annulus (g) at the same time (Fig. 1). The ratios $h: f, j: f$, and $(h+j): f$ were measures of the closeness of the papillary muscles to the interventricular septum ( $f$ is the endocardial circumference of the left ventricle) and e:f a measure of the closeness of the papillary muscles to each other (Fig. 2). We excluded from further analysis those patients who underwent surgery between cardiac catheterisation and echocardiography, those in whom the interval between cardiac catheterisation and cross sectional echocardiographic study was greater than three days, and those who had post-

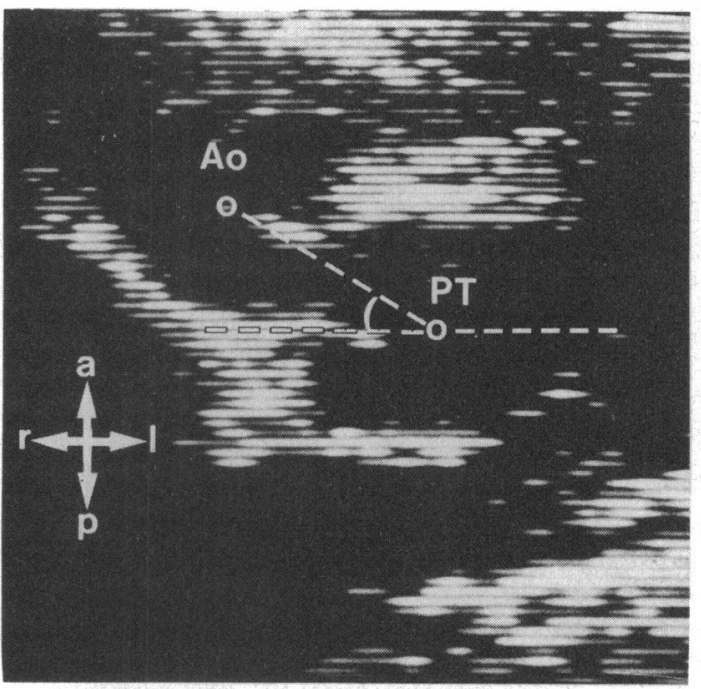

Fig. 3 Parasternal short axis cut at the level of the great vessels showing the method of measurement of the angle between them. A horizontal line was drawn through the midpoint of the pulmonary munk $(P T)$ and a further line was drawn to join this to the midpoint of the aorta $\left(A_{0}\right)$. The angle between these lines was the great vessel angle. $a$, anterior; $l$, left; $p$, posterior; $r$, right.

operative studies only. Forty patients formed the remaining study group ( 26 male and 14 female, aged 0-497 days mean 79.6). Twenty two patients were aged $<3$ days and all of them had cross sectional echocardiography on the same day as the haemodynamic study. We analysed the haemodynamic and cross sectional echocardiographic measurements by Student's $t$ test and by multiple regression analysis using the Statistical Package for the Social Sciences (version 7.0 Northwestern University) on an Amdahl mainframe computer.

\section{Results}

Pronounced septal bulge was common in patients with no pressure gradient between left ventricle and pulmonary artery. Thus septal bulge on its own did not necessarily indicate either fixed or dynamic obstruction. Seven patients had fixed abnormalities of the left ventricular outflow tract recognised by cross sectional echocardiography. In two this was a subpulmonary membrane (Fig. 4) analogous to a subaortic membrane seen in patients with normally related great vessels. In one this was confirmed at operation. In another the tension apparatus of the mitral valve appeared to be inserted into the ventricular septum (Fig. 5) and this was much more obvious in real time scanning than on still frames.

In the remaining four cases there was pronounced 


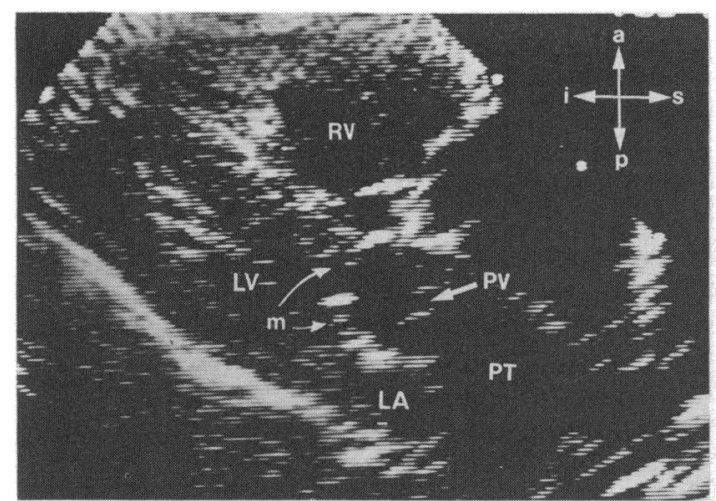

Fig. 4 Apical long axis cross sectional echocardiographic cut showing a subpulmonary membrane $(m)$ attached to both the interventricular septrom and anterior mitral leaflet below the pulmonary valve (PV). a, anterior; $i$, inferior; $L V$, left ventricle; LA, left atrivon; p, posterior; $P T$, bifiurcating, posteriorly situated pulmonary trunk; $R V$, right ventricle; $s$, superior.

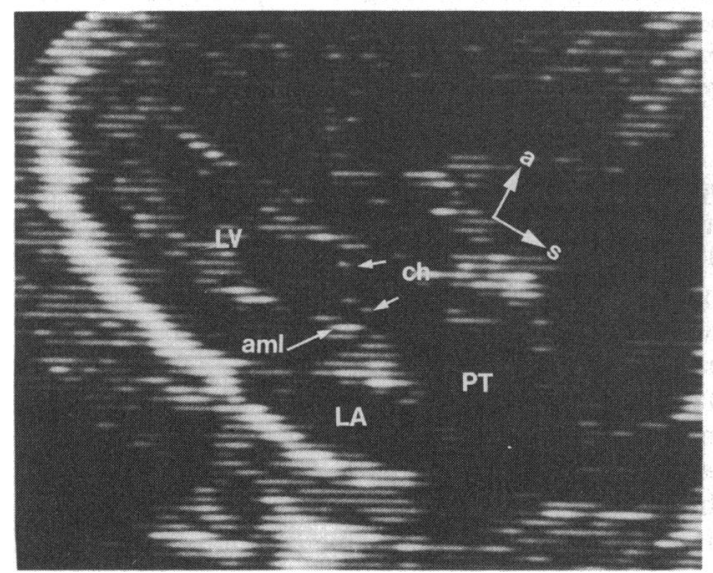

Fig. 5 Parasternal long axis cross sectional echocardiographic cut showing abnomal chordal attachment (ch) from the anterior mitral leaflet (aml) to the interventricular septum across the left ventricular outflow tract. a, anterior; $L A$, left atrivon; $L V$, left ventricle; $P T$, pulmonary trunk; s, superior.

thickening and ridge formation either about halfway along the anterior mitral leaflet or on the left side of the interventricular septum directly opposite this point, or else at both points (Fig. 6a and b). Real time scanning in these four patients showed that there was a characteristic motion of the septum and anterior and posterior mitral leaflets, such that in systole the relatively immobile anterior leaflet was firmly clamped between septum and posterior leaflet, thus producing left ventricular outflow obstruction. This pattern was quite distinct from that found in patients with septal
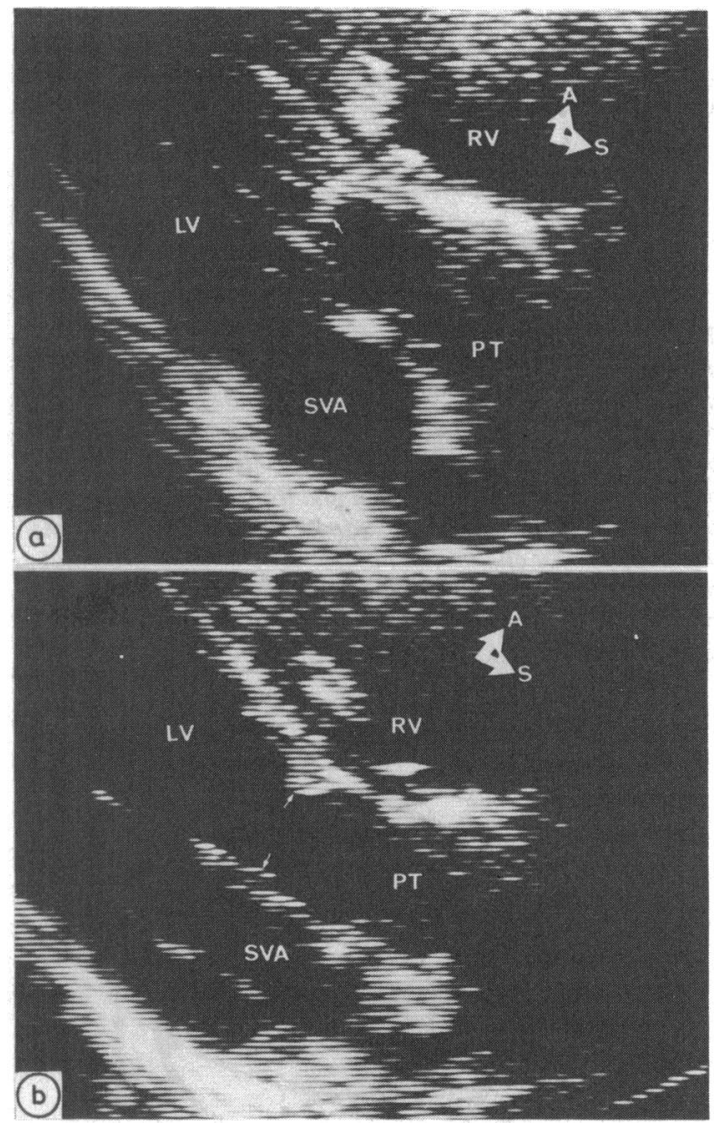

Fig. 6 Parasternal long axis cuts from a patient with fibrous thickening (arrows) on the interventricular septal endocardial surface at the point of mitral septal apposition and on the anterior mitral leaflet . a, anterior; $L A$, left atrivo; $L V$, left ventricle; $p$, posterior; $P T$, pulmonary trunk; $R V$, right ventricle; $s$, superior; SVA, systemic venous atrium.

bulge alone; although the septum bulged posteriorly in these patients, the anterior mitral leaflet was not squeezed. In two of the four patients with this form of septal and mitral obstruction, successive cross sectional echocardiograms showed progressive anatomical obstruction but cardiac catheterisation was not repeated. Systolic pressure gradients were known in five of the seven patients with fixed obstruction (20, $30,56,63$, and $100 \mathrm{~mm} \mathrm{Hg}$ ). The gradient of $20 \mathrm{~mm}$ $\mathrm{Hg}$ occurred in a patient with a membrane a few millimetres below the pulmonary valve and the $30 \mathrm{~mm}$ gradient in another patient who had excessive thickening of the anterior mitral leaflet and the interventricular septum at their point of apposition. The four patients with septal/mitral apposition were analysed separately, but no significant correlations were found between systolic gradients and geometric variables, 
apart from that expected with d:g.

The only statistically significant $(p<0.001)$ difference in mean values of left ventricular geometric ratios and haemodynamic variables between the groups with and without fixed obstruction was that for $d: g$ ratios (fixed obstruction $n=7, d: g=0.002$, no (fixed obstruction $n=40, d: g=0 \cdot 1870$ ).

Patients who had no cross sectional echocardiographic evidence of anything other than uncomplicated septal bulge were included in the "no fixed obstruction" group for analysis. They had systolic gradients ranging from 0 to $40 \mathrm{~mm} \mathrm{Hg}$ (mean (SD) $15 \cdot 1$ (2.7)). The highest gradients found were $21,35,38$, and 40 $\mathrm{mm} \mathrm{Hg}$. None of these patients had angiocardiographic, surgical, or necropsy (one patient) evidence of fixed obstruction.

\section{LONG AXIS MEASUREMENTS}

The ratio $c:(a+b)$ was directly related to right ventricular peak systolic pressure $(r=0.277, p=0.042$, $\mathrm{n}=40$ ) and $\mathrm{c:g}$ was directly related to right ventricular pressure $(r=0.350, p=0.013, n=40)$ (Fig. 7), and possibly to the amount by which right ventricular systolic pressure exceeded left ventricular systolic pressure $(r=0.261, p=0.052, n=40)$. No measure of septal bulge or septal eccentricity correlated with the systolic gradient from left ventricle to pulmonary artery. The ratio d:g was inversely, albeit weakly, related to systolic gradient $(r=0.403, p=0.048, n=18)($ Fig. 8) and to the amount by which right ventricular systolic pressure exceeded left ventricular systolic pressure $(\mathrm{r}=0.295, \mathrm{p}=0.032, \mathrm{n}=40)$. This ratio $\mathrm{d}: \mathrm{g}$ was directly related to left ventricular systolic pressure $(r=0.271, p=0.046, n=40)$ and pulmonary arteriolar resistance index $(r=0.692, p=0.006, n=12)$. Among the patients in whom fixed obstruction was excluded

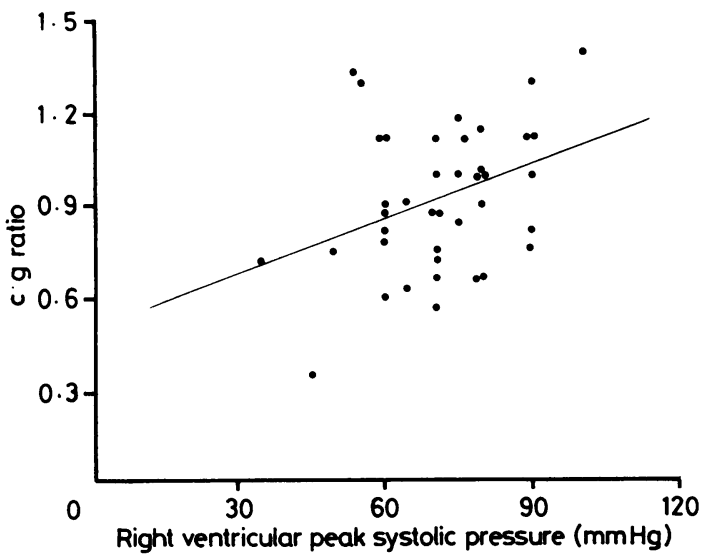

Fig. 7 Correlation of the ratio c:g (a measure of degree of septal bulge) and peak right ventricular systolic pressure $(n=40$, $r=0.350, p=0.013$ ).

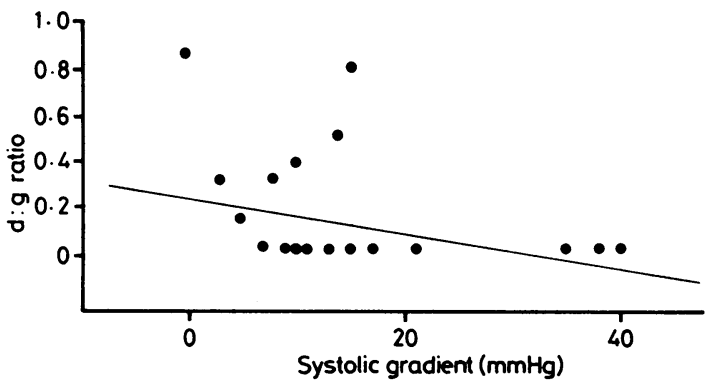

Fig. 8 Correlation between the ratio d:g (a measure of the minimam systolic distance between the anterior mitral leaflet and the interventricular septom) and peak systolic gradient across the left ventricular outflow tract $(n=18, r=-0403, p=0.048)$.

echocardiographically, only those whose gradient from left ventricle to pulmonary artery was $<20 \mathrm{~mm}$ $\mathrm{Hg}$ did not have complete mitral/septal apposition $(\mathrm{d}: \mathrm{g}=0)$ at end systole (Fig. 9). When d:g was zero, however, there were similar numbers of patients with gradients greater than and less than $20 \mathrm{~mm} \mathrm{Hg}$, indicating that systolic apposition of the anterior mitral leaflet to the septum is not necessarily associated with obstruction.

\section{SHORT AXIS MEASUREMENTS}

Neither closeness of the papillary muscles to each other (e:f), nor closeness of the individual papillary muscles (h:f, $j: f)$ to the interventricular septum were

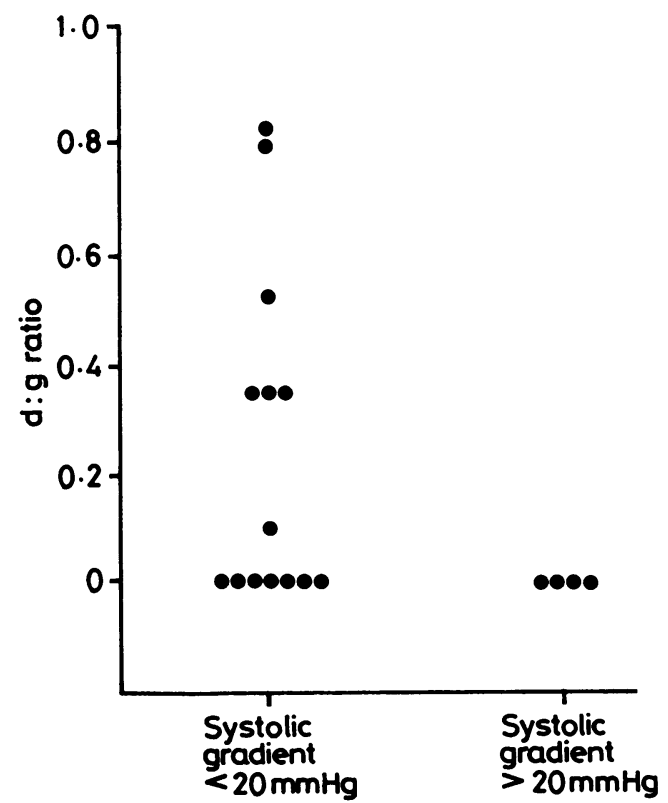

Fig. 9 Comparison of d:g ratios in patients with peak systolic gradients of $>20 \mathrm{~mm} \mathrm{Hg}$ and $<20 \mathrm{~mm} \mathrm{Hg}$ across the left ventricular outflow tract. 
significantly related to any haemodynamic variable. There was no significant correlation between any long axis measurement and the short axis measurements, but d:g was related to septal bulge $(\mathrm{c}:(\mathrm{a}+\mathrm{b}))$ $(\mathrm{r}=-0.516, \mathrm{p}=0.001, \mathrm{n}=40)$.

\section{SHORT AXIS MEASUREMENT OF GREAT VESSEL}

\section{ANGLE}

The angle between the aorta and pulmonary trunk was not significantly related to systolic gradient or to the ratio of ventricular systolic pressures but it was positively related to $h: f(r=0.597, p=0.045, n=9)$ and $(h+j): f(r=0.852, p=<0.002, n=9)$ (Fig. 10).

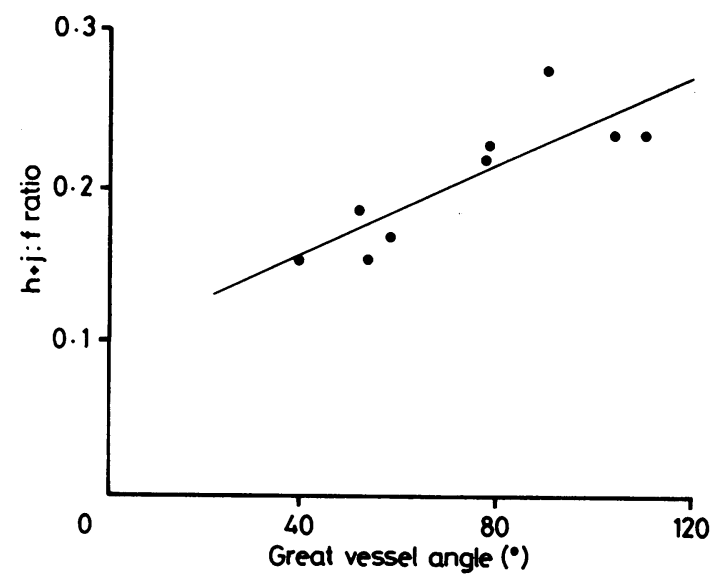

Fig. 10 Correlation of the ratio of the sum of the distances of the mitral papillary muscles fram the interventricular septum $h+j$ (see Fig. 6) to the endocardial circuonference $(f)$ of the left ventricle with great vessel angle (see Fig. 6$)(n=9, r=0852$, $p<0.002$ ).

\section{Discussion}

Despite many published reports, little is understood about the origin of left ventricular outflow tract obstruction in simple transposition of the great vessels when the ventricular septum is intact. Postmortem studies give no information on the haemodynamic consequences of septal bulge. The information that we have is derived from haemodynamic studies, angiocardiography, and $M$ mode and pulsed Doppler echocardiography. In simple transposition there is usually some gradient between the left ventricular peak systolic pressure and the pulmonary artery pressure. ${ }^{7}$

In an angiocardiographic study, Silove and Taylor implicated anterior movement of the mitral valve in systole as the cause of left ventricular outflow tract obstruction. They drew attention to the similarities between the appearance of the line of contact between the mitral valve and septum in simple complete transposition and that in hypertrophic obstructive cardiomyopathy. ${ }^{7}$ They reached this conclusion, however, after selecting 17 patients with intact ventricular septum and an anatomical abnormality which was visible on frontal and lateral plane angiocardiography from among 41 patients with peak systolic gradients of $\geqslant 15 \mathrm{~mm} \mathrm{Hg}$ between left ventricle and pulmonary artery. They were not able to explain the presence of this gradient in 16 of the remaining 24 patients in whom no angiocardiographic abnormality was present in the left ventricular outflow tract. Sansa and colleagues used axial cineangiographic techniques to determine the angiocardiographic features of left ventricular outflow tract obstruction in transposition. ${ }^{15}$ Their study confirmed the presence of most of the anatomical abnormalities associated with left ventricular outflow tract obstruction, including septal bulge, but pressure measurements made at cardiac catheterisation were not given.

Most investigations by $M$ mode and pulsed Doppler echocardiography have not distinguished between patients with and those without ventricular septal defect. This makes interpretation of most of the results difficult, since it would be surprising if patients with complete transposition and ventricular septal defect, in whom a fibromuscular subpulmonary tunnel is common, did not have abnormalities in $M$ mode and pulsed Doppler echocardiographic recordings. Nanda and colleagues reported that transposition with left ventricular outflow tract obstruction was characterised by diastolic mitral/septal apposition, a pulmonary artery small in comparison with the aorta, localised subpulmonary narrowing on scanning from left ventricle to pulmonary artery and, in a few patients, anterior motion of the mitral valve in systole, asymmetric septal hypertrophy, and systolic closure of the pulmonary valve. ${ }^{16} \mathrm{Few}$ of these criteria have become established. Aziz and colleagues distinguished between two types of obstruction, "fixed" in which the diameter of the left ventricular outflow tract compared with the diameter of the pulmonary artery was reduced throughout the cardiac cycle and in which there was no systolic anterior motion of the mitral valve, and "dynamic", in which the left ventricular outflow tract was wide open during diastole but narrowed in systole. ${ }^{17}$ All these patients with dynamic obstruction had anterior motion of the mitral valve in systole. Seven out of eight patients with "fixed" obstruction had an associated ventricular septal defect and, of those patients with so called dynamic obstruction, two had a ventricular septal defect. Fifteen out of the total of 16 patients had already undergone repair of transposition by Mustard's operation. Furthermore, the mean systolic pressure gradient between left ventricle and pulmo- 
nary artery in the patients with dynamic obstruction was only modest $(23.2(12.9) \mathrm{mm} \mathrm{Hg})$. There was no difference in the ratio between the left ventricular outflow tract diameter and the pulmonary artery diameter in patients with dynamic obstruction and patients with no obstruction at all. These workers subsequently reported further findings in a much larger series of patients, ${ }^{18}$ including 36 with left ventricular outflow tract obstruction, but their results are again difficult to interpret because they do not distinguish between patients with and those without ventricular septal defect. Silverman and colleagues showed that systolic anterior motion of the mitral valve occurred in six out of 10 patients after Mustard's operation for simple transposition; all six had a peak systolic left ventricular/pulmonary artery gradient of $\leqslant 25 \mathrm{~mm} \mathrm{Hg} .{ }^{19}$

Johnson et al, evaluated 21 consecutive children with simple transposition before interatrial repair and found no correlation between the presence of a haemodynamic pressure gradient from the left ventricle to the pulmonary artery and any of the features previously regarded as diagnositic of left ventricular outflow tract obstruction, including systolic anterior motion of the mitral valve, pulmonary valve flutter, and premature closure of pulmonary valve during systole. ${ }^{20}$ Pulsed Doppler velocimetry detected left ventricular outflow tract obstruction in complete transposition of the great arteries ${ }^{21}$ but gave no indication of the severity of obstruction. The number of patients with an intact ventricular septum was not stated.

Although septal bulge is prevalent in simple transposition after the first few days of life $\mathrm{e}^{22}$ and has been implicated in left ventricular outflow tract obstruction $^{5} 6$ little work has been done to confirm its role in the development of this obstruction. Our results suggest that septal bulge is usually associated with, and presumably the result of, the high right ventricular pressure and low pulmonary vascular resistance that typify patients with simple transposition. The greater the difference between the right and left ventricular systolic pressures, and the lower the pulmonary vascular resistance, the more the left ventricle is squashed by the right ventricle. These cross sectional echocardiographic findings in patients with complete transposition accord with those reported, with a single exception, in patients without transposition. ${ }^{23} 24$

We found no correlation between the degree of septal bulge and peak systolic gradient across the left ventricular outflow tract and only a very weak correlation between that gradient and the degree of proximity of the anterior mitral valve leaflet to the septum. These findings are surprising in view of the fact that Yacoub and colleagues found that left ventricular outflow tract gradients disappeared in patients studied before and after anatomical correction of simple transposition. 5 Reversing the pressures in the two ventricles would presumably reduce septal bulge and therefore the left ventricular outflow gradient if this were the cause of the gradient. Other factors, such as reduction in flow, may account for the disappearance of the outflow gradient after anatomical correction.

Two aspects of mitral/septal apposition merit further discussion. Firstly, it is by no means always the result of systolic anterior motion of the mitral valve. In many patients parasternal long axis views show that such apposition is due to posterior septal motion rather than to anterior mitral displacement. Secondly, there may be complete apposition of the two structures in the absence of any gradient. The retrospective nature of this study does not allow us to explain this finding. In a prospective study where pressures, cross sectional echocardiograms, and electrocardiograms were measured simultaneously, it could be established whether complete apposition coincided with a lack of a gradient, and, if it did, the importance of timing of such apposition could be examined. If it were to occur sufficiently late in systole it might not produce obstruction, as has been suggested by Murgo and colleagues in hypertropic cardiomyopathy. ${ }^{25}$ Whatever the reason for the lack of association between mitral/septal apposition and left ventricular outflow tract obstruction, it seems clear that the term "dynamic left ventricular outflow tract obstruction" should either be clarified or abandoned. Such a condition certainly cannot be diagnosed on the basis of the echocardiogram or angiocardiogram alone.

Unlike Chiu and colleagues, ${ }^{13}$ we could find no correlation between the angle of the great vessels and the systolic gradient across the left ventricular outflow tract, but we did find that great vessel angle was significantly and positively related to $h: f$ and $(h+j): f$. The more the great arteries run side by side the less wedged was the pulmonary valve and the nearer were the papillary muscles to the septum.

Our findings confirm that cross sectional echocardiography can identify some fixed abnormalities of the left ventricular outflow tract in cases of simple transposition. We cannot exclude the possibility that fixed obstruction was present but missed; but since fixed obstruction is rare in anatomical specimens it is unlikely that many errors were made. We have also shown that when the left ventricular outflow tract appears to be normal the gradient across it will be $<20$ $\mathrm{mm} \mathrm{Hg}$. We have used cross sectional echocardiography to demonstrate that thickening of the interventricular septum and anterior mitral leaflet at their point of coaptation can cause progressive anatomical left ventricular outflow tract obstruction in some patients, as Tynan and colleagues have suggested might occur. ${ }^{6}$ 
This confirms what has long been suspected from pathological studies - that the fibrous plaque seen on both septum and anterior mitral leaflet is acquired rather than congenital.

PJR was supported by the Wellcome Trust, and FJM and RKHW by the Vandervell and British Heart Foundations.

\section{References}

1 Leanage R, Agnetti A, Graham G, Taylor J, Macartney FJ. Factors influencing survival after balloon atrial septostomy for complete transposition of great arteries. Br Heart F 1981; 45: 559-72.

2 Shaher RM, Puddu GC, Khoury G, Moes CAP, Mustard WT. Complete transposition of the great vessels with anatomic obstruction of the outflow tract of the left ventricle. Surgical implications of anatomic findings. Am f Cardiol 1967; 19: 658-70.

3 Shrivastava S, Tadavarthy SM, Fukuda T, Edwards JE. Anatomic causes of pulmonary stenosis in complete transposition. Circulation 1976; 54: 154-9.

4 Moene RJ, Oppenheimer-Dekker A. Congenital mitral valve anomalies in transposition of the great arteries. $\mathrm{Am}$ f Cardiol 1982; 49: 1972-8.

5 Yacoub MH, Arensman FW, Keck E, Radley-Smith R. Fate of dynamic left ventricular outflow tract obstruction after anatomic correction of transposition of the great arteries. Circulation 1983; 68 (suppl II): 56-62.

6 Tynan M, Carr I, Graham G, Bonham-Carter RE. Subvalvar pulmonary obstruction complicating the postoperative course of balloon atrial septostomy in transposition of the great arteries. Circulation 1969; 39 (suppl I): 223-8.

7 Silove ED, Taylor JFN. Angiographic and anatomical features of subvalvular left ventricular outflow obstruction in transposition of the great arteries. The possible role of the anterior mitral valve leaflet. Pediatr Radiol 1973; 1: 87-91.

8 Crupi G, Anderson RH, Ho SY, Lincoln C. Complete transposition of the great arteries with intact ventricular septum and left ventricular outflow tract obstruction. Surgical management and anatomic considerations. $\mathcal{f}$ Thorac Cardiovasc Surg 1979; 78: 730-8.

9 Smallhorn J, Tommasini G, Deanfield J, Douglas J, Gibson D, Macartney F. Congenital mitral stenosis. Anatomical and functional assessment by echocardiography. Br Heart f 1981; 45: 527-34.

10 Wilcox WD, Seward JB, Hagler DJ, Mair DD, Tajik AJ. Discrete subaortic stenosis: two-dimensional echocardiographic features with angiographic and surgical correlation. Mayo Clin Proc 1980; 55: 425-33.

11 Daskalopoulos DA, Edwards WD, Driscoll DJ, Seward JB, Tajik AJ, Hagler DJ. Correlation of two-dimensional echocardiographic and autopsy findings in complete transposition of the great arteries. $\mathcal{F}$ Am Coll Cardiol
1983; 2: 1151-7.

12 Rosenquist GC, Taylor JFN, Stark J. Aortopulmonary fenestration and aortic atresia. Report of an infant with ventricular septal defect, persistent ductus arteriosus, and interrupted aortic arch. Br Heart f 1974; 36: 1146-8.

13 Chiu I, Anderson RH, Macartney FJ, de Leval MR, Stark J. Morphologic features of an intact ventricular septum susceptible to subpulmonary obstruction in complete transposition. Am f Cardiol 1984; 53: 1633-8.

14 Kappagoda CT, Greenwood P, Macartney FJ, Linden RJ. Oxygen consumption of children with congenital diseases of the heart. Clin Sci Mol Med 1973; 45: 10714.

15 Sansa M, Tonkin IL, Bargeron LM Jr, Elliott LP. Left ventricular outflow tract obstruction in transposition of the great arteries. An angiographic study of 74 cases. Am f Cardiol 1979; 44: 88-95.

16 Nanda NC, Gramiak R, Manning JA, Lipchik EO. Echocardiographic features of subpulmonic obstruction in dextro-transposition of the great vessels. Circulation 1975; 51: 515-21.

17 Aziz KU, Paul MH, Muster AJ. Echocardiographic assessment of left ventricular outflow tract in d-transposition of the great arteries. Am $\mathcal{F}$ Cardiol 1978; 41: 543-51.

18 Aziz KU, Flor Cruz RA, Paul MH, et al. M mode echocardiographic assessment of d-transposition of the great arteries and associated defects. Pediatr Cardiol 1982; 2: 131-40.

19 Silverman NH, Payot M, Stanger P, Rudolph AM. The echocardiographic profile of patients after Mustard's operation. Circulation 1978; 58: 1083-93.

20 Johnson GL, Cottrill CM, Noonan JA. False diagnosis of subpulmonary obstruction by echocardiography in d-transposition of the great arteries. Am $\mathcal{F}$ Cardiol 1982; 49: 1984-9.

21 Areias JC, Goldberg SJ, Spitaels SEC, de Villeneuve VH. An evaluation of range gated pulsed Doppler echocardiography for detecting pulmonary outflow tract obstruction in d-transposition of the great vessels. Am Heart $\mathcal{f}$ 1978; 96: 467-74.

22 Van Doesburg NH, Bierman FZ, Williams RG. Left ventricular geometry in infants with d-transposition of the great arteries and intact interventricular septum. Circulation 1983; 68: 733-9.

23 King ME, Braun $\mathrm{H}$, Goldblatt $A$, Liberthson $R$, Weyman AE. Interventricular septal configuration as a predictor of right ventricular systolic hypertension in children: a cross-sectional echocardiographic study. Circulation 1983; 68: 68-75.

24 Shimada R, Takeshita A, Nakamura M. Noninvasive assessment of right ventricular systolic pressure in atrial septal defect: analysis of the end-systolic configuration of the ventricular septum by two-dimensional echocardiography. Am f Cardiol 1984; 53: 1117-23.

25 Murgo JP, Alter BR, Dorethy JF, Altobelli SA, McGranahan GMF Jr. Dynamics of left ventricular ejection in obstructive and non-obstructive hypertrophic cardiomyopathy. F Clin Invest 1980; 66: 1369-82. 